\title{
College Students' Self-Acceptance: A Paint Therapy Group Counseling Intervention
}

\author{
Zheng Qiu-Qiang $\mathbb{D}^{1,2,3}$ Liang Wen-Jun, ${ }^{2}$ Fan Wan-Yi, ${ }^{2}$ and Zhang Qi-Zhe ${ }^{3}$ \\ ${ }^{1}$ Mental Health Education and Counseling Center, Beijing Normal University Zhuhai, Zhuhai 519087, Guangdong, China \\ ${ }^{2}$ Education College, Beijing Normal University Zhuhai, Zhuhai 519087, Guangdong, China \\ ${ }^{3}$ Institute of Analytical Psychology, City University of Macao, Macau 999078, China
}

Correspondence should be addressed to Zheng Qiu-Qiang; zqq@bnu.edu.cn

Received 17 June 2021; Revised 22 July 2021; Accepted 31 July 2021; Published 10 August 2021

Academic Editor: Mian Ahmad Jan

Copyright () 2021 Zheng Qiu-Qiang et al. This is an open access article distributed under the Creative Commons Attribution License, which permits unrestricted use, distribution, and reproduction in any medium, provided the original work is properly cited.

\begin{abstract}
This research highlights the effect of paint therapy group counseling on college students' achievement in the field of education. For this purpose, we have used a quasiexperimental design with pretest/posttest of control group and experimental group. The sample used in our experiment consists of 18 students at a university in Guangdong Province. Participants were randomly assigned to two groups, i.e., experimental group and control group, and completed pretest and posttest measures of self-acceptance and selfevaluation over 2 months. The difference between the two groups before and after the intervention was determined using an independent-samples $t$-test. We have also used a paired-sample $t$-test to compare the effects of the intervention on the experimental achievement scores of the groups. The results showed that the self-acceptance score in the experimental group's posttest was $40.78 \pm 6.91(t=3.66, p<0.01)$, while the scores of self-acceptance factor and self-evaluation factor were $20.67 \pm 4.12$ $(t=3.19, p<0.05)$ and $20.11 \pm 3.59(t=3.71, p<0.01)$, respectively. Besides, the two months, posttest follow-up showed that the self-acceptance score was $43.67 \pm 4.64(t=1.0, p<0.05)$, and the scores of self-acceptance factor and self-evaluation factor were $22.11 \pm 2.85(t=4.06, p<0.01)$ and $21.56 \pm 2.65(t=2.86, p<0.05)$, respectively.
\end{abstract}

\section{Introduction}

Self-acceptance is crucial during the shift from a child to an independent adult. Self-acceptance refers to the positive and negative characteristics individuals attribute to themselves [1]. Categorized as one of the many critical issues under Rational Emotive Behavior Therapy [2, 3], self-acceptance acknowledges "one is a complex, imperfect human being capable of making mistakes" [4]. To this end, individuals are encouraged to refrain from self-criticism of their body image, self-worth, and giving credence to other's people's negative judgments [4]. This perception of self is also integral to a person's self-evaluation, with young people undergoing varying levels of emotions that correlate with their feelings of self-worth. Negative self-evaluations, coupled with hormones, and stress (real or imagined) contribute to feelings such as depression and result in the breakdown in psychological health. Conversely, positive self-evaluation assists with goal setting, as well as motivational and performance improvement, and is closely annexed to selfknowledge and self-consciousness [5]. Accordingly, Albert Ellis argues self-evaluation's importance in the acceptance of self and others [6].

For young people, college is a period of adaptation with incremental development tasks toward self-identity [7] and adulthood [8]. Self-evaluation and self-acceptance contribute to students' psychological health and well-being and are important factors in their coping and emotional skills and social interactions [9]. Numerous studies have highlighted the adverse effects of poor self-concept among college students to include episodes of eating disorders, pregnancy, mental health issues, and high attrition [10]. To address these disorders, researchers have found that the self-acceptance levels of different groups such as male drug addicts [11], 
primary school students [12], juvenile offenders [13], and vocational school students [14] were positively affected by group counseling. Group counseling allows for multifaceted issues to be addressed in a single session [8]. Effective group counseling techniques include psychotherapies such as hypnotherapy [15], imagery dialogue [16], dance movement therapy [17], and sports games [18]. Paint or art therapy is another technique that has the unique advantage of incorporating relaxing and joyful activities while simultaneously reducing negative subconscious symptoms. Using an experimental-comparison research design, the authors in [19] conducted art therapy intervention using clay to demonstrate the positive effects on college students' anxiety levels over ten weeks. The authors in [9] sought feedback from 68 participants after their participation in 12 different art therapy groups. Most of the participants (98\%) reported positive impacts on their psychological health. The efficacy of this treatment in self-acceptance among college students is an underresearched albeit burgeoning area in the discipline, with published studies indicating varying levels of success.

The aim of this study, therefore, is to explore the effects of a paint therapy group (PTG) counseling intervention on college students' self-acceptance level using an experimental pretest-posttest follow-up control group design. The study is conducted at a university in China and is significant for the sharing of expressions and emotions in a predominantly conservative society. The following hypothesis is proposed: group paint therapy counseling can improve college students' self-acceptance level. The main contributions of this work are as follows:

(1) The aim was to improve the self-acceptance level of college students by using paint therapy group counseling technique.

(2) The scores of self-acceptance factor and self-evaluation factor were improved.

(3) The self-acceptance questionnaire (SAQ) score, selfacceptance factor, and self-evaluation factor of the control group, during this work, had no significant difference when comparing pretest and posttest. Hence, this revealed that the PTG counseling intervention has a positive effect on the self-acceptance level of the subjects.

(4) Independent-samples $t$-test was conducted on the self-acceptance levels of the two groups but there was no statistically significant difference.

The rest of this paper is organized as follows: In Section 2 , we explain material and methodology used for this work; in Section 3, we discuss our experimental work and its results; Section 4 presents discussion and limitation of our proposed scheme, and finally conclusion is presented in Section 5 .

\section{Material and Methodology Used}

2.1. Paint Therapy (Art Therapy). Art is the item or cycle of purposely organizing things (frequently with representative importance) such that it affects and influences at least one of the faculties, feelings, and insight. It is anything but an assorted scope of human exercises, manifestations, and methods of articulation, including music, writing, film, photography, figure, and works of art. Meanwhile, the utilization of creative techniques to treat mental problems and upgrade emotional wellness is known as paint therapy (art therapy). Paint therapy is a strategy established in the possibility that imaginative articulation can cultivate mending and mental prosperity [20]. The advantages of paint therapy are listed as follows:

(1) Therapy should be centered on personal development, rehabilitation, psychotherapy, correction, adaption, and/or personality enhancement

(2) Integrate personal training in art and therapy with the understanding of theories of normal and abnormal behavior, graphic symbolic expression, and intervention strategies to respond to clients' strengths and needs

(3) Individual or group work with people of various ages in a collection of settings reduces the severity of depression or anxiety problems

(4) Assist customers who are suffering with illness, trauma, or loss

(5) Reduce work/school-related stress

(6) Interpersonal interactions should be improved

(7) Assist clients in increasing their self-awareness and self-esteem, improving their cognitive capacities, and/or encouraging creativity and personal growth

(8) Patient care services are provided

2.2. Group Counseling. Group counseling is a type of counseling in which a small number of people meet on a routine basis to talk about, interact with, and explore issues with one another and the leader of the group. Group therapy aims to provide a safe and comfortable environment in college for learners to sort out their problems and emotional concerns. Participants gain insight into their ideas and actions and offer advice and support to others. Other advantages of group counseling are listed as follows:

(1) Support is given and received

(2) Investigate potential solutions after gaining a better knowledge of the issues

(3) In a secure group context, practice interpersonal skills

(4) Discover more about how others perceive you

(5) Improve observation and feedback abilities

(6) Improve problem-solving abilities

(7) Enhance emotional expression

(8) Reduce social isolation

(9) Improve communication abilities

Depending on the mental health condition as well as the therapeutic procedure employed during the counseling, counseling can be classified into many forms. 
Cognitive behavioral groups: this type focuses on discovering and altering incorrect or distorted thought processes, emotional reactions, and behaviors

Interpersonal groups: this type focuses on interpersonal relationships and social interactions, such as how much assistance you receive and how these relationships affect your mental health

Psychoeducational groups: this type focuses on educating patients about their diseases and coping mechanisms, generally using cognitive behavior therapy (CBT) ideas

Skills development groups: this type focuses on helping people with mental illnesses or physical disorders improve their social skills

Support groups: people with a variety of mental health disorders, as well as their loved ones, can benefit from this form of treatment

2.3. Subjects. Eighteen participants were selected after undergoing a screening process. Volunteers were recruited through posters and texts on WeChat public accounts posted at Beijing Normal University Zhuhai, China, and comprised students from education, management, business, and Chinese colleges. $72 \%$ of the participants were females, with mean age of $19 \pm 19$ years. All participants came from urban families.

2.4. Procedure. The University Ethics Committee approved the research plan and all participants signed informed consents. Group leaders were teachers and student assistants of the university's counseling center and had received professional training in clinical psychology and group counseling. Participants were randomly divided into two groups: the experimental group $(n=9 ; 7$ females and 2 males) and the control group ( $n=9 ; 6$ females and 3 males). The experimental group received eight weeks of paint therapy group counseling, while the control group received none.

Selection of research subjects underwent two stages. In the first stage, 78 participants were interviewed. Two aspects were addressed for inclusion: (1) participants' basic human condition (i.e., physical state, emotion, conflict, etc.) and willingness to participate in the self-acceptance group counseling and (2) introduction of the study objective and in-depth clarification in response to questions. In the second stage, after the interviews, six subjects who were diagnosed with a mental disorder and were receiving drug treatment were excluded. Remaining subjects were screened, and the self-acceptance level scores from the remaining subjects were measured and ranked from high to low. Subjects who scored in the top $27 \%$ were set as the high group and those who scored in the last $27 \%$ placed in the low group. Eighteen subjects were randomly selected from the low group, which were then randomly assigned to the experimental group as well as to the control group. Independent-samples $t$-test was conducted on the self-acceptance levels of the two groups but there was no statistically significant difference.

\section{Methods}

3.1. Measuring Instruments. In this research work, we have adopted [21] self-acceptance questionnaire (SAQ) which is a commonly used questionnaire in China. Our SAQ consists of 16 items divided into two subscales: self-acceptance and self-evaluation. Self-evaluation (SE) refers to the judgment and evaluation of one's own thoughts, expectations, behaviors, and personality characteristics, which is an important condition of self-regulation [22]. During our experiment, the eight self-acceptance items $(1,4,7,8,11,13$, 14 , and 16) were scored reversely on a 4-point Likert scale $(1=$ very opposite to, $4=$ very similar $)$. The higher the score is, the higher the degree of self-acceptance of the research object is and vice versa. Similarly, the eight self-evaluation items $(2,3,5,6,9,10,12$, and 15$)$ were scored positively on a 4 -point Likert scale ( $1=$ very similar to, $4=$ very opposite). From this, we concluded that the higher the score is, the higher the degree of self-acceptance of the research object is and vice versa.

Cronbach's alpha is a metric for determining the internal logic or reliability of a test or scale item. Cronbach's alpha is calculated by comparing the variance of all single-item scores to the total score for each observation. Cronbach's alpha for our proposed scheme can be seen by

$$
\alpha=\frac{N P}{V+(N-1) \cdot P},
$$

where $N$ is the total number of participants; $P$ represents average covariance between participants-pairs; and $V$ represents average variance.

Therefore, Cronbach's coefficient alpha for internal consistency of the self-acceptance factor and self-evaluation factor in our scheme were .93 and .91 , respectively, while the correlation coefficient between the two factors was .37 $(p<0.0001)$, and the retest reliability of the questionnaire was .77, indicating a good validity [23].

3.2. Design of the Experiment. We used a quasiexperimental approach with collaborative learning as the instructional model and typical lecture technique groups, similar to [24]. Because of its resistance to frequent risks to validity and reliability, this is called experimental research design. Figure 1 illustrates a methodical framework for the design.

Due to the scope of the issue and the study hypotheses, we have chosen this design. Following a selection process, a total of eighteen volunteers were selected for the experiment. In addition, students from education, management, business, and Chinese universities were recruited using posters and texts put on WeChat public accounts at Beijing Normal University Zhuhai, China. The majority of the participants (72\%) were females, with an average age of 19-19 years. The study has two groups: an experimental group of 9 students and a control group of 9 students.

We conducted an activity in which we divided a total of eighteen participants into two groups. Each group was given a subsubject from a larger issue and asked to create display charts that explained it in detail. Both groups gave 


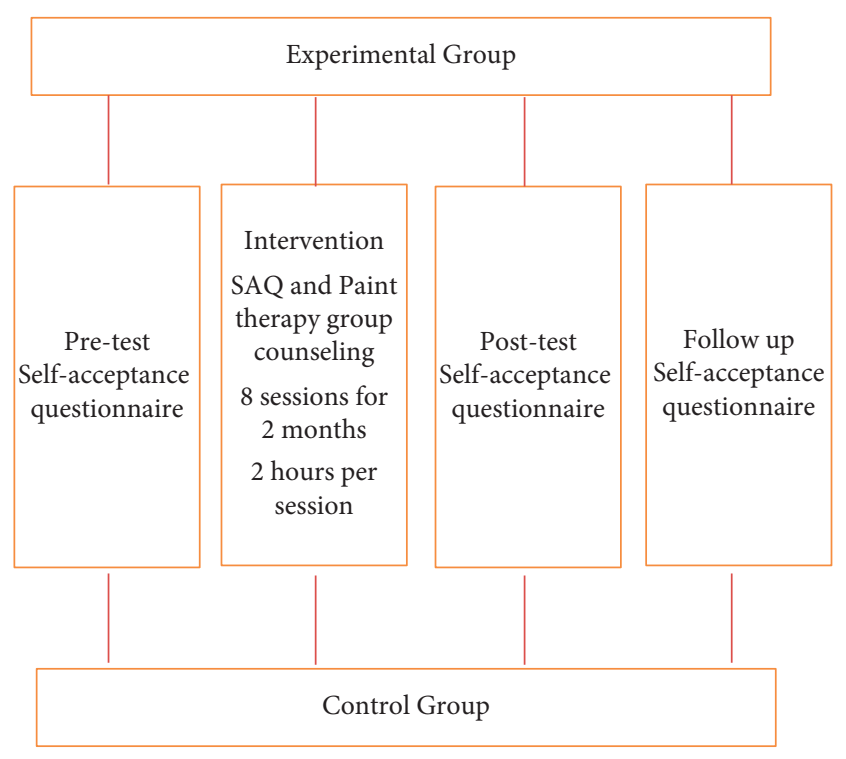

Figure 1: Research design.

presentations on their respective projects. Figures 2 and 3 illustrate the procedure.

3.3. Data Analysis. The data were analyzed using the SPSS software version 19 . The paired-sample $t$-tests were applied to compare the mean pretest and posttest scores (see Table 1). The independent-samples $t$-test was used to compare the means of two independent groups.

3.4. Ideas and Scheme of Group Counseling. In [25], the authors described self-acceptance as one of the most important characteristics of self-actualized people. Group counseling for self-acceptance occurred during three phases. Group sessions took place in the group counseling room at the university. At the beginning, group facilitators created an atmosphere of empathy and support by introducing themselves and encouraging each person to share sincerely and openly. The first step was "permission," which meant opening oneself subconsciously. At this stage, the group facilitators guided participants to a state of complete openness or receptiveness through breathing and relaxation exercises. These breathing exercises varied from seconds to minutes depending on the situation. The second step was "awareness." At this point, participants learned about themselves by listening to their body and inner feelings and visualizing their external image, behavior, emotions, and inner thoughts. An individual can express their emotional experience, thoughts, and subconscious feelings through colors without too much conscious thinking. Participants reviewed the works created in the group and interpreted their own works. Discussions that ensued among group members helped them to rediscover themselves and gain a deeper and broader understanding of self. The third step, "acceptance," was based on a comprehensive and objective self-evaluation, including self-acceptance of personal strengths and weaknesses and differences between ideal self

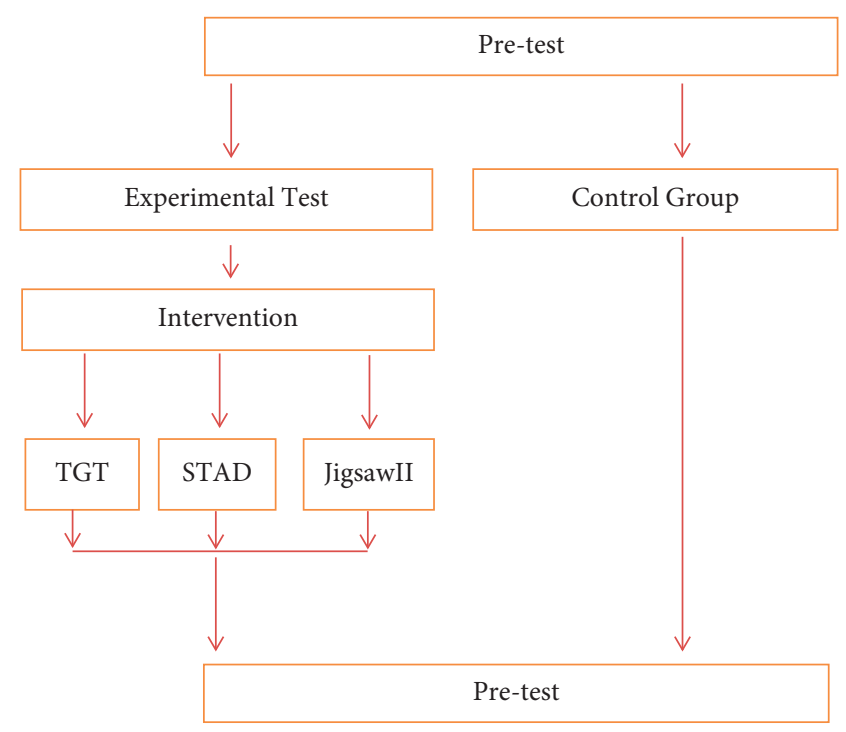

FIgURE 2: Pretest-posttest control group experimental design.

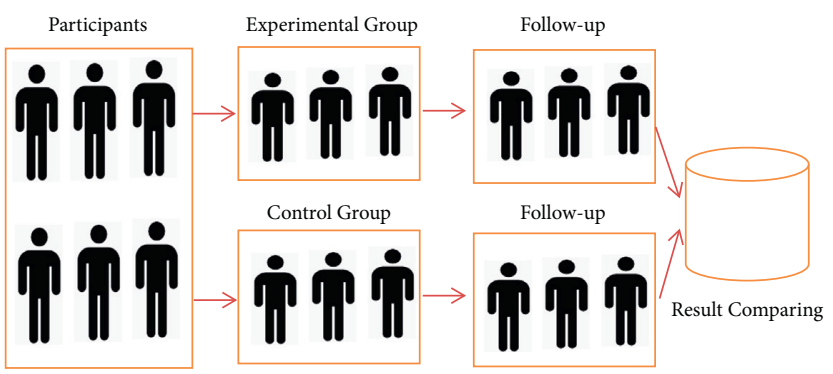

Figure 3: Random control trial.

and true self [26]. Painting therapy group counseling scheme is shown in Table 1.

\section{Experimental Work and Results}

In this section, we explain our experimental work and its results obtained during our work. We have used independent-samples $t$-test to measure the mean scores difference between achievement scores of control and treatment groups on pretest.

4.1. Comparison of Self-Acceptance between the Experimental Group and the Control Group before and after the Experiment. The SAQ score of the experimental group was higher before the test, with a significant difference in the data $(p<0.01)$. The scores of self-acceptance factor and self-evaluation factor were improved, and statistical results are significantly different $(p<0.05)$. However, the SAQ score, selfacceptance factor, and self-evaluation factor of the control group showed no significant difference before and after the test. Therefore, it is suggested that the PTG counseling intervention has a positive effect on the self-acceptance level of the subjects. 


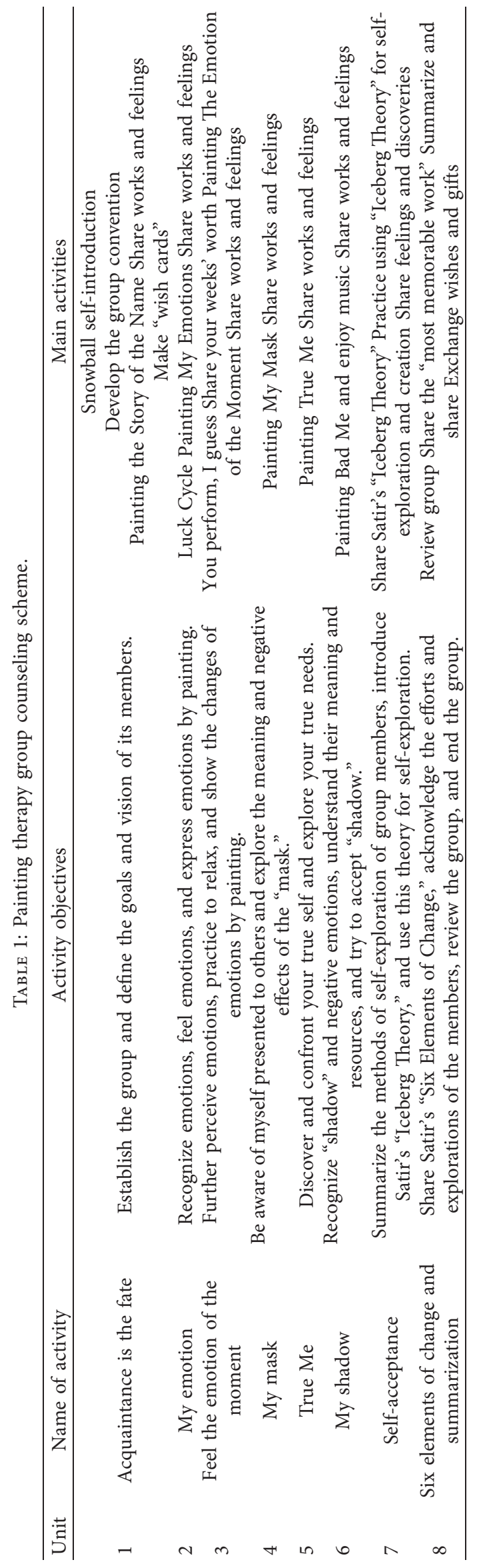


Comparison of self-acceptance scores of different groups of college students before and after painting therapy group counseling $(x \pm s)$ is shown in Table 2 .

\subsection{Comparison of Follow-Up Self-Acceptance between the} Experimental Group and the Control Group Two Months after the Experiment. The follow-up SAQ score after 2 months in the experimental group was higher than that before the test, and there was a statistically significant difference $(p<0.01)$. Among them, the scores of self-acceptance factor and selfevaluation factor were improved with significant differences $(p<0.05)$ which can be seen in Table 3. However, the SAQ score, self-acceptance factor, and self-evaluation factor of the control group showed no significant difference before and after the test. Therefore, it implies that the PTG counseling intervention had a continuous effect on improving the subjects' self-acceptance level.

There is no significant difference between the two groups ( $p=0.01)$, as shown in the table below. It means that, before the intervention, both groups were performing at the same level. Independent-samples $t$-test for pretest of participants achievement is shown in Table 4.

Similarly, Table 5 shows that there is no significant difference between the two groups $(p<0.05)$. Independentsamples $t$-test for posttest of participants achievement is shown in Table 5. Paired $t$-test for pretest/posttest is shown in Table 6.

To examine the effect of an intervention on experimental group's accomplishment scores, we used a paired-samples $t$ test as shown in the table above. The table reveals that the pretest $(M=9.12, \mathrm{SD}=2.421)$ and posttest $(M=10.25$, $\mathrm{SD}=1.18)$ accomplishment scores were significantly different; $t(50)=-9.17, p<0.001$.

The change trends of the total PTG score were identical for all participants in the intervention class, as shown in Figure 4 .

The factual examination of the information utilizing the $t$-test uncovered that the scores of our proposed scheme in the pretest were fundamentally higher than those in the posttest and follow-up tests for three elements of our work: in the component of posttest and follow-up related tests, the scores of the pretest and posttest were essentially higher than those of the subsequent test. As displayed in Figure 4, the changing pattern of the complete score of the CIAS-R was comparative for all subjects in the experimental group.

4.3. Discussion. The aim of this study was to explore the effects of a paint therapy group counseling intervention on college students' self-acceptance level using an experimental pretest-posttest control group design.

We tested the hypothesis that PTG counseling can improve college students' self-acceptance level. Pairedsamples $t$-tests showed a significant improvement in the experimental group's self-acceptance factor and self-evaluation factor. This result supported our hypothesis. The independent-samples $t$-test shows that the intervention effect of PTG counseling on college students' self-acceptance level is continuous and significant.
Data analysis of the pretest and posttest PTG counseling showed that, after eight weeks of painting, the level of the total score of the experimental group was significantly improved, as well as the self-acceptance factor and selfevaluation factor. However, the measured data of the control group's subjects did not change significantly before the test and at follow-up and there was no regularity. In the followup test conducted two months after the intervention, the self-acceptance score of the subjects in the experimental group was still high, which was significantly different from the self-acceptance score measured before the intervention. This suggests that the PTG counseling intervention had a positive lasting effect on college students' self-acceptance level. Compared with the data before the intervention, the improvement of self-acceptance factors measured two months after the intervention was more than that of selfevaluation, which may improve the self-evaluation level of the subjects in a short period, thus affecting the improvement of self-acceptance level.

Through artistic expressions, PTG counseling greatly reduced the psychological defense mechanism and resistance of group members. Through painting, individuals were able to project unhealthy emotional stressors into works, express their feelings and experiences into the creative process, relieve psychological anxiety, and eliminate problem behaviors [27]. The humanistic treatment orientation created a group member-centered atmosphere so participants felt valued and accepted. Participants reported feeling their inner life energy, learnt to see themselves realistically and objectively, accepted themselves, and finally completed their self-perfection and self-integration. This was a more acceptable approach for sensitive participants who had a greater stress response and low self-esteem. Participants were able to fully open themselves in a relaxed and trusted environment, freely create art, and connect with their subconscious. In this way, their subconscious thoughts were revealed naturally, so that the group leader had a specific understanding of participants' real situation through the colors, lines, shapes, texture, and other expressions of the paintings and so was able to guide them to see and accept their own subconscious contents. Artistic creation has its own process of psychological therapy [28]. Participants expressed emotions through their painting that they found difficult to do ordinarily in their daily life. On the basis of group dynamics theory [29], PTG counseling facilitated group cohesiveness, harmonized the internal atmosphere, stimulated participants' creative thinking process (those who actively participated in the activities), and created a harmonious, warm, and positive atmosphere. Consequently, participants felt accepted and secure enough to trust one another, thus enabling their ability to show their inner feelings and encourage more self-exploration. The words, behaviors, views, and attitudes of group participants became admirable references for other members to emulate. In the process of group counseling, participants constantly adjusted their insights by empathizing with other participants' behaviors, emotions, and thoughts. They also observed the facilitator's communication style, which helped them to learn additional appropriate ways to communicate. In this 
TABLE 2: Comparison of self-acceptance scores of different groups of college students before and after painting therapy group counseling $(x \pm s)$.

\begin{tabular}{|c|c|c|c|c|c|c|}
\hline Survey time & Group & $\begin{array}{c}\text { Number of } \\
\text { members }\end{array}$ & Statistics & $\begin{array}{l}\text { Self-acceptance } \\
\text { factor } \\
\end{array}$ & $\begin{array}{l}\text { Self-evaluation } \\
\text { factor } \\
\end{array}$ & $\begin{array}{c}\text { Total self-acceptance } \\
\text { score } \\
\end{array}$ \\
\hline \multirow[t]{4}{*}{ Before experiment } & $\begin{array}{l}\text { Experimental } \\
\text { group }\end{array}$ & 9 & & $18.11 \pm 3.69$ & $19.22 \pm 2.17$ & $37.33 \pm 4.39$ \\
\hline & Control group & 9 & & $16.89 \pm 2.71$ & $18.22 \pm 2.49$ & $35.11 \pm 2.15$ \\
\hline & & & $t$ value & 0.80 & 0.91 & 1.37 \\
\hline & & & $p$ value & $>.05$ & $>.05$ & $>.05$ \\
\hline \multirow[t]{5}{*}{ After experiment } & $\begin{array}{l}\text { Experimental } \\
\text { group }\end{array}$ & 9 & & $20.67 \pm 4.12$ & $20.11 \pm 3.59$ & $40.78 \pm 6.91$ \\
\hline & Control group & 9 & & $16.78 \pm 2.77$ & $18.00 \pm 2.78$ & $34.78 \pm 2.05$ \\
\hline & & & $t$ value & 3.19 & 3.71 & 3.66 \\
\hline & & & $p$ value & $<.01$ & $<.01$ & $<.05$ \\
\hline & & & $\mathrm{d}$ value & 1.13 & 0.66 & 1.34 \\
\hline \multirow{5}{*}{$\begin{array}{l}\text { Two months after the } \\
\text { experiment }\end{array}$} & $\begin{array}{l}\text { Experimental } \\
\text { group }\end{array}$ & 9 & & $22.11 \pm 2.85$ & $21.56 \pm 2.65$ & $43.67 \pm 4.64$ \\
\hline & Control group & 9 & & $16.75 \pm 2.75$ & $18.09 \pm 2.58$ & $34.84 \pm 2.06$ \\
\hline & & & $t$ value & 4.06 & 2.86 & 4.33 \\
\hline & & & $p$ value & $<.01$ & $<.05$ & $<.01$ \\
\hline & & & $\mathrm{d}$ value & 1.91 & 1.33 & 2.64 \\
\hline
\end{tabular}

TABLE 3: Satisfaction survey score of experimental group.

\begin{tabular}{lcc}
\hline Measures & Month 1 & Month 2 \\
\hline Self-acceptance score in the experimental group after the test & $40.78 \pm 6.91(t=3.66, p<0.01)$ & $43.67 \pm 4.64(t=1.0, p<0.05)$ \\
Self-acceptance factor scores & $20.67 \pm 4.12(t=3.19, p<0.05)$ & $22.11 \pm 2.85(t=4.06, p<0.01)$ \\
Self-evaluation factor scores & $20.11 \pm 3.59(t=3.71, p<0.01)$ & $21.56 \pm 2.65(t=2.86, p<0.05)$ \\
\hline
\end{tabular}

TABLE 4: Independent-samples $t$-test for pretest of participants achievement.

\begin{tabular}{|c|c|c|c|c|c|}
\hline Variable & $N$ & Mean & $\mathrm{df}$ & $t$ value & $\begin{array}{c}\text { Average } \\
\text { covariance }(\mathrm{P})\end{array}$ \\
\hline Experimental group & 9 & 9.12 & 50 & 0.188 & 0.01 \\
\hline Control group & 9 & 9.10 & 50 & 0.188 & 0.01 \\
\hline
\end{tabular}

TABLE 5: Independent-samples $t$-test for posttest of participants achievement.

\begin{tabular}{lccccc}
\hline Variable & $N$ & Mean & df & $t$ value & Sig. \\
\hline Experimental group & 9 & 10.25 & 50 & 0.188 & 0.000 \\
Control group & 9 & 10.10 & 50 & 2.15 & 0.000 \\
\hline
\end{tabular}

$p<0.05$.

TABLE 6: Paired $t$-test for pretest/posttest.

\begin{tabular}{llcccc}
\hline & & Mean diff. & SD & $T$ & $\begin{array}{c}\text { 2-tailed } \\
\text { sig. }\end{array}$ \\
\hline $\begin{array}{l}\text { Pair } \\
(p<0.01)\end{array}$ & $\begin{array}{l}\text { Pretest- } \\
\text { posttest }\end{array}$ & -3.200 & 1.25 & -9.17 & $0.000^{* * *}$ \\
\hline
\end{tabular}

way, the facilitator or group leader can deepen participants' understanding and also learn more about themselves.

4.4. Limitations. Paint therapy group counseling highlighted two significant issues with its implementation. First, to counter any possible stigma of psychological problems,

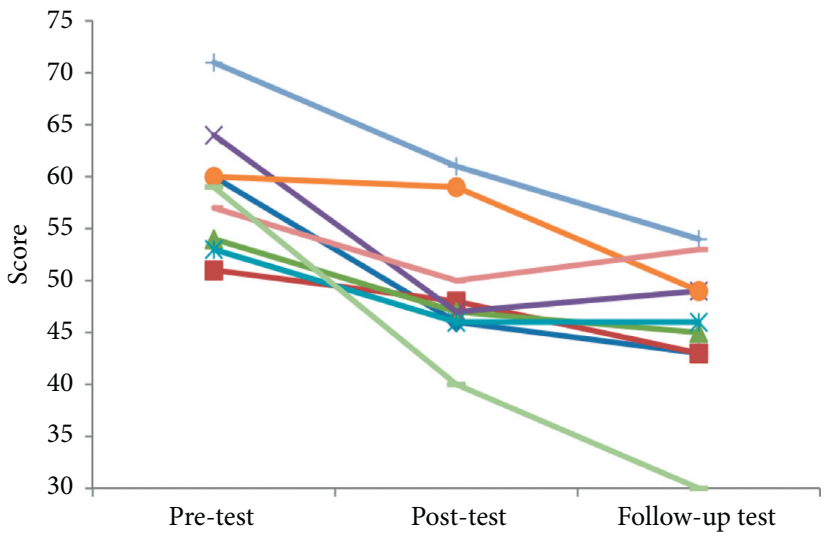

FIgURE 4: Total score in the experimental group $(n=9)$.

especially in the university setting, the researchers had to rename the group "self-acceptance - painting spiritual growth group" during the recruitment drive. This was intended to spark interest and enthusiasm among college students and encourage them to participate. It was easy to generate empathy among participants in the group, when they experienced similar problems and understood these from other participants' viewpoints. These common feelings allowed participants to lower their defensive mechanisms and engendered trust in the group. Second, aspects of "psychological education" were integrated into group counseling activities to help participants better understand 
the way of self-acceptance and learn how to change their selfcognition and behaviors. For instance, in the process of PTG counseling, Satir's Iceberg Theory and Six Elements of Change were applied in units 7 and 8 to help participants better understand, accept, and change themselves [30]. Participants' feedback demonstrated attempts to incorporate learning theories into their daily and study life with positive results.

\section{Conclusions}

This research work presents a paint therapy group counseling intervention for self-acceptance of the students at a university in Guangdong Province. We have conducted a quasiexperiment during which we have created two groups: one is the experimental group and the other is a control group. The participants were randomly and equally assigned to these two groups ( $n=9$ in both groups) and completed pretest and posttest measures of self-acceptance and selfevaluation over 2 months. We have also used a pairedsamples $t$-test to compare the effect of the intervention on the experimental achievement scores of the groups. It can be concluded from the results that paint therapy group counseling had a positive effect on the academic achievement of students enrolled in the subject of education. The outcome suggests that this is an ideal psychological counseling program for college students with low degrees of selfacceptance. On this basis, future researchers may consider exploring alternative forms of group counseling within the higher education settings, which may be more acceptable or culturally relevant to college students, to help them experience better self-acceptance and growth.

\section{Data Availability}

The datasets used and/or analyzed during the current study are available from the corresponding author upon reasonable request.

\section{Conflicts of Interest}

The authors declare that there are no conflicts of interest.

\section{References}

[1] F. F. D. Morgado, A. N. N. Betanho Campana, and M. D. Fernandes Tavares, "Development and validation of the self-acceptance scale for persons with early blindness: the SAS-EB," PLoS One, vol. 9, no. 9, Article ID e106848, 2014.

[2] A. Ellis, Reason and Emotion in Psychotherapy: A Comprehensive Method of Treating Human Disturbances, Carol Publishing, Johnson City, TN, USA, 1994.

[3] A. Ellis, "Rational emotive behavior therapy," in Current Psychotherapies, R. C. D. Wedding, Ed., Thomson Brooks/ Cole, Boston, MA, USA, 8th edition, 2008.

[4] M. Bernard, "Self-acceptance: REBT as the psychological armor that protects children and adolescents," in RationalEmotive and Cognitive-Behavioral Approaches to Child and Adolescent Mental Health: Theory, Practice, Research, ApplicationsSpringer, Berlin, Germany, 2020.
[5] Z. A. Konzelmann, "Self-evaluation: philosophical perspectives," in Philosophical Studies Series:, Z. A. Konzelmann, K. Lehrer, and H. Schmid, Eds., Self-evaluation Springer, Dordrecht, Netherland, 2011.

[6] M. E. Bernard, "Dispute irrational beliefs and teach rational beliefs: an interview with Albert Ellis," Journal of RationalEmotive and Cognitive-Behavior Therapy, vol. 27, no. 1, pp. 66-76, 2009.

[7] S. Widodo, D. P. Sari, R. Hikmawan, and N. W. A. Majid, "Profile of student's self- acceptance and their habits of minds," in Proceedings of the International Conference on Elementary Education, pp. 1165-1177, March 2020, http://proceedings2.upi. edu/index.php/icee/article/view/729.

[8] A. Sonnone and J. S. Rochford, "Wellness at universities: a group art therapy approach," Journal of College Counseling, vol. 23, no. 2, pp. 168-179, 2020.

[9] M. Rankanen, "Clients'," The Arts in Psychotherapy, vol. 50, pp. 101-110, 2016.

[10] N. S. M. Arshadh and T. E. A. T. Muda, "A review of social acceptance, psychosocial implications and coping mechanisms of teenage mothers," International Journal of Social Science Research, vol. 2, no. 1, pp. 1-12, 2020.

[11] Y. Pang, Q. Zhou, Y. Chen, M. Zhuang, P. Luo, and X. Zheng, "The intervention study of group counseling on the self-acceptance and coping styles of male drug addicts under compulsory rehabilitation," Psychological Research, vol. 63, no. 3, pp. 44-51, 2007.

[12] L. Zhu, "An empirical study of group counseling on improving pupils' psychological resilience and self-acceptance," Journal of Heihe University, vol. 10, no. 4, pp. 39-44, 2019.

[13] H. Smeijsters, J. Kil, H. Kurstjens, J. Welten, and G. Willemars, "Arts therapies for young offenders in secure care-A practice-based research," The Arts in Psychotherapy, vol. 38, no. 1, pp. 41-51, 2011.

[14] L. Yao and Y. Lin, "Study on the ways to promote the selfacceptance level of vocational students through focus resolution orientation group counseling," Journal of Taiyuan Urban Vocational College, vol. 211, no. 2, pp. 100-101, 2019.

[15] Y. Zhang and G. Xu, "A research on the application of hypnotic group therapy in order to improving self-acceptance of college students," Journal of Psychological Science, vol. 2, no. 1, pp. 236-238, 2006.

[16] F. Du, A Comparative Study of Hypnotherapy and ImageDialogue Techniques on the Intervention of Self-Acceptance in Higher Vocational Students, Yangzhou University, Yangzhou, China, 2012.

[17] X. Xuan, J. Wu, H. Ma, H. Li, S. Xu, and Y. Chen, "Effects of dance movement therapy on self-acceptance and self-efficacy in college students," Chinese Journal of Clinical Psychology, vol. 25, no. 3, pp. 584-587, 2017.

[18] C. Wang, A Study on the Relationship between Self-Acceptance and Social Anxiety and its Intervention in College Freshmen, Hebei Normal University, Shijiazhuang, China, 2016.

[19] M. E. Beerse, T. Van Lith, and G. D. Stanwood, "Is there a biofeedback response to art therapy? A technology-assisted approach for reducing anxiety and stress in college students," SAGE Open, vol. 9, no. 2, Article ID 2158244019854646, 2019.

[20] H. L. Stuckey and J. Nobel, "The connection between art, healing, and public health: a review of current literature," American Journal of Public Health, vol. 100, no. 2, pp. 254263, 2010.

[21] Z. Cong and W. Gao, "Preparation of self-acceptance questionnaire and reliability validity test," Chinese Journal of Behavioral Medicine and Brain Science, vol. 1, pp. 20-22, 1999. 
[22] H. L. Andrade, "A critical review of research on student selfassessment," Frontiers in Education, vol. 4, 2019.

[23] G. W. Heiman, Understanding Research Methods and Statistics, Houghton Mifflin Comp, Boston, MA, USA, 2nd edition, 2008.

[24] D. Campbell, J. Stanley, and N. Gage, Experimental and Quasi-Experimental Designs for Research, R. McNally, Chicago, IL, USA, 1966.

[25] L. P. Meyer and M. Leppma, "The role of mindfulness, selfcompassion, and emotion regulation in eating disorder symptoms among college students," Journal of College Counseling, vol. 22, no. 3, pp. 211-224, 2019.

[26] Y. Zhou and F. Zi, "The relationship between self-esteem and self-acceptance-based on the three components of selfawareness (social science edition)," Journal of Luo Yang Institute of Science and Technology, vol. 8, no. 2, pp. 81-84, 2016.

[27] A. C. Abbing, E. W. Baars, O. Van Haastrecht, and A. S. Ponstein, "Acceptance of anxiety through art therapy: a case report exploring how anthroposophic art therapy addresses emotion regulation and executive functioning," Case reports in psychiatry, vol. 2019, Article ID 4875381, 13 pages, 2019.

[28] X. Zhang, J. He, and F. Fan, "The application of expressive art group counseling in primary and secondary school teachers' psychological intervention in the third year after the earthquake [social sciences edition)," Journal of Lanzhou University of Arts and Science, vol. 33, no. 1, pp. 120-124, 2017.

[29] G. Nash, "Response art in art therapy practice and research with a focus on reflect piece imagery," International Journal of Art Therapy, vol. 25, no. 1, pp. 39-48, 2020.

[30] J. Banmen, "The Satir model: yesterday and today," Contemporary Family Therapy, vol. 24, no. 1, pp. 7-22, 2002. 